\title{
Growth impacts in a changing ocean: insights from two coral reef fishes in an extreme environment
}

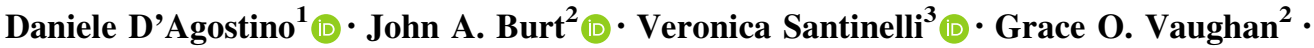

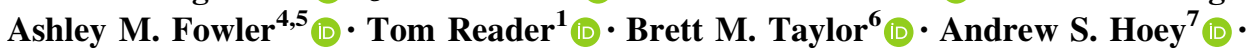 \\ Geórgenes H. Cavalcante ${ }^{8,9}$ (D) Andrew G. Bauman ${ }^{10}$ (1) David A. Feary ${ }^{11}$
}

Received: 1 June 2020/ Accepted: 8 January 2021

(C) The Author(s) 2021

\begin{abstract}
Determining the life-history consequences for fishes living in extreme and variable environments will be vital in predicting the likely impacts of ongoing climate change on reef fish demography. Here, we compare size-atage and maximum body size of two common reef fish species (Lutjanus ehrenbergii and Pomacanthus maculosus) between the environmentally extreme Arabian/Persian Gulf ('Arabian Gulf') and adjacent comparably benign Oman Sea. Additionally, we use otolith increment width profiles to investigate the influence of temperature, salinity and productivity on the individual growth rates. Individuals of both species showed smaller size-at-age and lower maximum size in the Arabian Gulf compared to conspecifics in the less extreme and less variable environment of the Oman Sea, suggesting a life-history trade-off
\end{abstract}

Topic Editor Dr. Alastair Harborne

Supplementary information The online version contains supplementary material available at (https://doi.org/10.1007/s00338021-02061-6)

Daniele D'Agostino

Dan.D'Agostino@nottingham.ac.uk

1 School of Life Sciences, University of Nottingham, Nottingham NG7 2RD, UK

2 Center for Genomics and system Biology and the Water Research Center, New York University Abu Dhabi, PO Box 129188, Abu Dhabi, United Arab Emirates

3 Department of Earth and Marine Sciences, University of Palermo, Via Archirafi 18, 90123 Palermo, Italy

4 New South Wales Department of Primary Industries, Sydney Institute of Marine Science, Mosman, NSW 2088, Australia

5 School of Life Sciences, University of Technology, Sydney, Broadway, NSW 2007, Australia between size and metabolic demands. Salinity was the best environmental predictor of interannual growth across species and regions, with low growth corresponding to more saline conditions. However, salinity had a weaker negative effect on interannual growth of fishes in the Arabian Gulf than in the Oman Sea, indicating Arabian Gulf populations may be better able to acclimate to changing environmental conditions. Temperature had a weak positive effect on the interannual growth of fishes in the Arabian Gulf, suggesting that these populations may still be living within their thermal windows. Our results highlight the potential importance of osmoregulatory cost in impacting growth, and the need to consider the effect of multiple stressors when investigating the consequences of future climate change on fish demography.

Keywords Ocean warming · TSR - Coping mechanism . Plasticity $\cdot$ Stress $\cdot$ Physiology $\cdot$ Oxygen limitation

6 Australian Institute of Marine Science, Crawley, WA 6009, Australia

7 ARC Centre of Excellence for Coral Reef Studies, James Cook University, Townsville 4811, Australia

8 Instituto de Ciências Atmosféricas, Universidade Federal de Alagoas, Maceió, Alagoas 57072-970, Brazil

9 Department of Biology, Chemistry and Environmental Sciences, American University of Sharjah, PO Box 26666, Sharjah, United Arab Emirates

10 Experimental Marine Ecology Laboratory, National University of Singapore, 21 Lower Kent Ridge Road, Singapore 119077, Singapore

11 MRAG Ltd, 18 Queen Street, London W1J 5PN, UK 


\section{Introduction}

Anthropogenic global climate change is having significant biological impacts on individuals, species and ecosystems (e.g. Parmesan and Yohe 2003; Bellard et al. 2012; Hughes et al. 2018; Gordon et al. 2018; Pratchett et al. 2018; França et al. 2020). Reductions in body size, coupled with reduction in lifespan (Munch and Salinas 2009), geographic shifts in species distribution (Walther et al. 2002; Parmesan and Yohe 2003; Feary et al. 2014) and changes in phenology (Walther et al. 2002; Stenseth 2002; Visser and Both 2005; Taylor 2008), are recognised as common responses to global warming in ectotherms (Daufresne et al. 2009; Gardner et al. 2011; Ohlberger 2013). Such reduction in body size is consistent with the temperaturesize rule (TSR) (i.e. body size decreases at higher temperature) (Atkinson 1994; Kingsolver and Huey 2008; Ohlberger 2013; Huss et al. 2019) and is particularly evident in aquatic environments (Forster et al. 2012; Horne et al. 2015), where fish and other aquatic organisms' average body size has already declined by $5-20 \%$ over the last two decades (Baudron et al. 2014; Audzijonyte et al. 2016; van Rijn et al. 2017). Experimental temperature-size responses, models and meta-analyses suggest that body size will further reduce by $3-5 \%$ per degree of warming in aquatic arthropods, while in fishes it may decline by $14-24 \%$ by 2050 under a higher green-house gases emission scenario (A2 scenario, IPCC 2007; Cheung et al. 2013; Pauly and Cheung 2018).

Decreasing fish sizes will impact fecundity and fisheries productivity (Baudron et al. 2014; Barneche et al. 2018), prey-predator interactions (Barnes et al. 2010) and overall ecosystem functioning (Bellwood et al. 2012; Cheung et al. 2013). Understanding what drives reductions in fishes' body size will be essential for predicting how populations are impacted by projected climate change. In this regard, despite the ubiquity of the TSR in describing the pattern of body size and temperature in a range of taxa, the underlying mechanisms of body size reduction with increasing temperature are still debated (Audzijonyte et al. 2019).

Projected increases in mean temperature and temperature variability due to climate change (i.e. 1.0 to $4.0{ }^{\circ} \mathrm{C}$ increase by 2100 , IPCC 2019) are likely to be particularly challenging for marine fish due to the greater energetic demands for routine metabolic activities (Gillooly et al. 2001; Pörtner and Knust 2007; Neuheimer et al. 2011; Rubalcaba et al. 2020) with, ultimately, less energy available for somatic growth. Similarly, projected intensification of the global water cycle $\left(4-8 \%{ }^{\circ} \mathrm{C}\right.$ of increase in surface air temperature change) and consequent increase in water salinity in already dry regions (Durack et al. 2012; Skliris et al. 2014; Zika et al. 2018) will likely increase the osmoregulation costs for many marine species (Boeuf and Payan 2001; Ern et al. 2014), especially those living in hypersaline semi-enclosed seas. Finally, climate change is predicted to alter the rate and distribution of primary production in the world's oceans (Brown et al. 2010; Stock et al. 2017), with consequent impacts on food availability and fish growth and biomass (Martino et al. 2019). While the relationship between ocean primary productivity and fish growth is clear (Downing et al. 1990), the direction and magnitude of this relationship can vary, from increased growth due to greater food availability to growth reduction associated with excessive primary production and ocean deoxygenation, especially in highly productive and variable environments (Martino et al. 2019; Tanner et al. 2019).

One approach to understanding how marine fish demography may be impacted by future environmental variance and extremes in temperature and salinity is to study contemporary communities that exist within naturally extreme and variable environments (Burt et al. 2020). Here, we compare the effect of water temperature, salinity and primary productivity on the size-at-age and growth rate of the coral reef fishes Lutjanus ehrenbergii and Pomacanthus maculosus between the environmentally extreme southern Arabian/Persian Gulf (hereafter 'Arabian Gulf') and comparatively more benign adjacent Oman Sea (Fig. 1). The Arabian Gulf has the largest thermal range $\left(>20^{\circ} \mathrm{C}\right)$ and highest maximum sea surface temperature (SST) experienced by extant coral reef fishes (winter: $<15{ }^{\circ} \mathrm{C}$, summer: $>35{ }^{\circ} \mathrm{C}$ ), with fishes enduring several months of conditions considered lethal to reef fishes in other parts of the world (Riegl and Purkis 2012; Rummer et al. 2014; Vaughan et al. 2019). In addition, present summer SSTs in the Gulf are comparable to those expected for tropical oceans by 2100 (Riegl and Purkis 2012; IPCC 2019), while winter temperatures can be so low as to induce cold water coral bleaching (Coles and Fadlallah 1991). Additionally, due to restricted water exchange through the narrow Strait of Hormuz, as well as limited freshwater input and high evaporation (Reynolds 1993, 2002), the Arabian Gulf's waters are characterized by hypersaline conditions (annual mean salinity $42 \mathrm{psu}$ ) that are the highest reported for coral reefs (Bauman 2013, Vaughan et al. 2019). In contrast, the Oman Sea is subject to less extreme and variable temperature and salinity, but a higher baseline and higher interannual variation of chlorophyll-a concentration (used as a proxy for primary productivity) due to seasonal upwelling events (Coles 2003, Bauman 2013).

Given differences in environmental conditions between the Arabian Gulf and the Oman Sea, we hypothesise that, in line with the TSR, (i) fishes in the Arabian Gulf would exhibit lower growth rates, as well as smaller size-at-age 
Fig. 1 Map of the study regions showing collection locations in the southern Arabian/Persian Gulf and northern Oman Sea (circles: field collection-reefs, triangles: local fish landing sites; refer to Table S2 for location names, coordinates and sampling method)

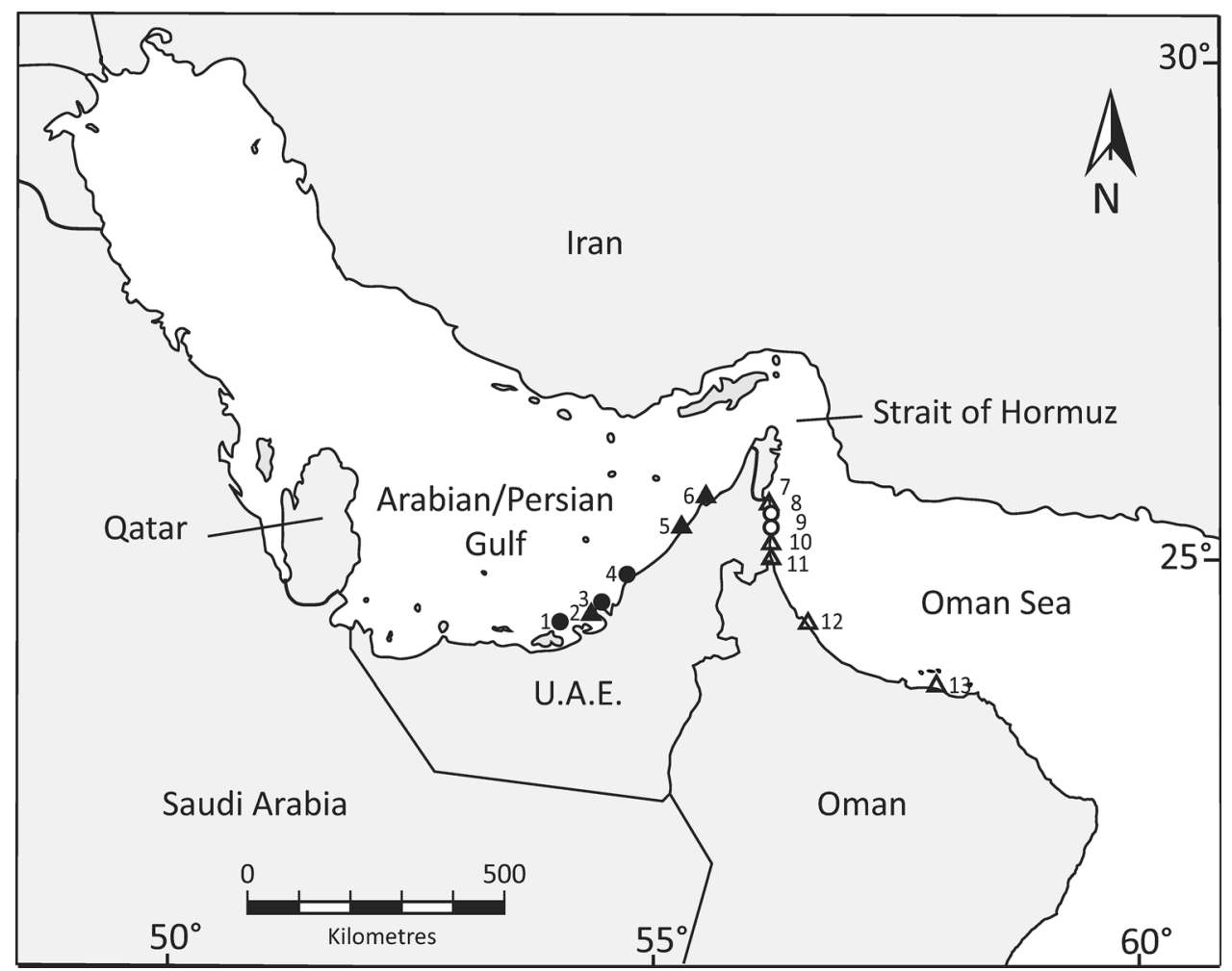

and maximum body size than conspecifics from the less extreme and less variable environment of the Oman Sea and (ii) that predicted differences in growth between populations (i.e. Arabian Gulf vs Oman Sea) would be driven by local environmental conditions. We investigated the role of temperature, salinity and productivity in structuring fish demography between regions by using an otolith sclerochronology approach and mixed-effect modelling and predicted that low growth rate and small body size would be the results of extreme temperature ranges in the Arabian Gulf, exacerbated by high salinity and lower primary productivity.

\section{Materials and method}

To determine whether fish growth is reduced in the Arabian Gulf compared to the Oman Sea and whether extreme environmental conditions are the drivers of somatic growth differences, we analysed the otolith structure of the blackspot snapper (Lutjanus ehrenbergii, F. Lutjanidae [Peters, 1869]) and the yellow-bar angelfish (Pomacanthus maculosus, F. Pomacanthidae [Forsskål, 1775]). Both $L$. ehrenbergii and $P$. maculosus are coral-associated species commonly found on nearshore patch and fringing reefs throughout both regions (Feary et al. 2010; Burt et al. 2011) and are known to have highly determinate growth patterns (Grandcourt et al. 2010; 2011). Furthermore, the two species were chosen because they are phylogenetically and ecologically disparate: L. ehrenbergii is a generalist carnivore, feeding on benthic invertebrates associated with turfing algae (i.e. amphipods, isopods) and small fish (Randall 1995; D'Agostino et al. 2019), while P. maculosus is a facultative spongivore/corallivore (Shraim et al. 2017).

\section{Sample collection of focal species for life-history comparison}

Sample collection encompassed six sites within the Arabian Gulf (three reefs and four local fish landing sites, spanning from Dhabiya to Umm Al Quwain) and seven sites within the Oman Sea (two reefs and five local fish landing sites, spanning from Dibba to As Seeb) (Fig. 1, Table S2). As both species are relatively site attached and the nearest sites between the two regions were separated by more than $300 \mathrm{~km}$ (Grizzle et al. 2016; Burt et al. 2016), negligible movement between regions was predicted (Buchanan et al. 2019). Fish sourced from landing sites were purchased and sampled only upon confirmation of their local origin from the fisherman. Individuals collected in situ (i.e. from the reefs) were collected using the fish anaesthetic clove oil (juveniles) or spear guns (sub-adults and adults) and euthanized using an ice slurry. Upon collection, all individuals were measured (standard length 
[SL], nearest $\mathrm{mm}$ ), weighed (total weight, nearest $\mathrm{g}$ ) and sagittal otoliths removed, cleaned in ethanol and stored dry.

\section{Age determination}

To determine age, 1012 and 210 otoliths were sectioned from L. ehrenbergii and P. maculosus specimens, respectively (Table 1). Each otolith was ground to the nucleus to produce a thin transverse section $(\sim 300 \mu \mathrm{m})$ and mounted on a microscope slide using established procedures (i.e. Taylor and McIlwain 2010). Otoliths were examined under transmitted light with a low power microscope and individual ages estimated by counting the number of annual increments, or annuli, along the dorsal antisulcus axis of each otolith (Fig. 2). Previous studies have verified the deposition of annual increments for both species (Grandcourt et al. 2010; 2011). Blind reads (with respect to size and collection location) of annual increments were performed by the first author (DD) on three separate occasions for each specimen. Final age was determined when two or more counts agreed, and the precision of age estimation was calculated using the index of average percentage error (IAPE) (following Wakefield et al. 2017). If agreement was not achieved after three counts, the sample was excluded from the analysis. For individuals $<1$ year, otolith sections were further ground with lapping film, polished by hand with $0.3 \mu \mathrm{m}$ alumina powder and viewed through a compound microscope by one of the co-authors (BMT). For these individuals, age was then estimated by counting the number of daily increments, with three blind reads performed for each individual. Final age for juvenile fishes was taken as the median of three counts when all counts were within $10 \%$ of the median. Samples with counts $>$ $10 \%$ of the median were excluded from the analysis.

\section{Population-level growth, body size and life span}

To model and compare the population growth rate of $P$. maculosus and L. ehrenbergii between the Arabian Gulf and the Oman Sea, the re-parameterised version of the von Bertalanffy growth function (rVBGF, Francis 1988) was used (Visconti et al 2018). The rVBGF describes growth based on modelled body size of individuals at three ages, $\mathrm{L}_{\tau}, \mathrm{L}_{\omega}$ and $\mathrm{L}_{\mu}$, allowing a direct comparison of mean sizeat-age data between populations. Age $\tau$ was selected to reflect the ascending part of the growth trajectory (i.e. the period of fast, early growth), $\omega$ represents the onset of a reduction in growth rate, while $\mu$ represents the asymptote of growth (i.e. when growth reaches a plateau) (Trip et al. 2008, 2014). To model species growth based on the trajectory of the region-specific growth curves, ages 1 and 5 years (based on annuli counts) were taken as $\mathrm{L}_{\tau}$ (hereafter ' $\mathrm{L}_{1}$ ') and $\mathrm{L}_{\mu}$ (hereafter ' $\mathrm{L}_{5}$ '), respectively, while $\mathrm{L}_{\omega}$ was calculated at 3 years (hereafter ' $\mathrm{L}_{3}$ '). The rVBGF model was fitted using the age (years) and length data ( $\mathrm{mm}$ SL) of each sample and by constraining the curve to a length of settlement of $10 \mathrm{~mm}$ SL (Grandcourt et al. 2011). The best-fit model parameters, $\mathrm{L}_{1}, \mathrm{~L}_{3}$ and $\mathrm{L}_{5}$, describing each dataset were determined by minimising the negative $\log$ of the likelihood, given a probability density function with a Poisson distribution (Haddon 2001).

Mean maximum age (hereafter 'Age $\max _{\max }$ ') and mean maximum body size (hereafter ' $\mathrm{L}_{\text {max }}$ ') were estimated for both species in each region. Age $\mathrm{max}_{\max }$ and $\mathrm{L}_{\max }$ were taken, respectively, as the average age (years) and body size (SL) of the $25 \%$ oldest or largest adult (i.e. $\geq 3$ years old) individuals, respectively (Trip et al. 2008, 2014). Differences in mean $\mathrm{Age}_{\max }$ and $\mathrm{L}_{\max }$ between populations were analysed using linear models.

Table 1 Details of Lutjanus ehrenbergii and Pomacanthus maculosus otolith samples used to investigate differences in growth between the Arabian Gulf and the Oman Sea. Site and species-specific growth

\begin{tabular}{llllllllllll}
\hline Species & Area & $n$ & $\begin{array}{l}\text { Size range } \\
(\mathrm{mm})\end{array}$ & $\begin{array}{l}\text { Age (days- } \\
\text { years) }\end{array}$ & $\begin{array}{l}\text { Age }_{\max } \\
(\mathrm{SE})\end{array}$ & $\mathrm{L}_{\max }(\mathrm{SE})$ & $\mathrm{L}_{1}$ & $\mathrm{~L}_{3}$ & $\mathrm{~L}_{5}$ & $-\lambda$ & $\sigma$ \\
\hline $\begin{array}{c}\text { Lutjanus } \\
\text { ehrenbergii }\end{array}$ & Arabian Gulf & 873 & $33-224$ & $38-15$ & $8.58(0.41)$ & $199.52(1.91)$ & 132.54 & 186.31 & 189.45 & 4071.80 & 25.53 \\
Pomacanthus & Arabian Gulf & 139 & $18-282$ & $27-16$ & $11(0.53)$ & $246.21(3.71)$ & 144.72 & 216.52 & 223.12 & 695.66 & 34.81 \\
maculosus & Oman Sea & 42 & $4-262$ & $9-31$ & $14.62(1.14)$ & $197.48(4.94)$ & 95.12 & 160.65 & 170.48 & 841.03 & 36.12 \\
& & $40-264$ & $81-22$ & $8.55(1.93)$ & $227.11(6.55)$ & 107.34 & 177.83 & 188.34 & 204.78 & 28.65
\end{tabular}

$n$, sample size; $\mathrm{L}_{1}$, mean size-at-age one; $\mathrm{L}_{3}$, age three; $\mathrm{L}_{5}$, age five; $-\lambda$, negative log-likelihood; $\sigma$, standard deviation. All sizes are in mm $\mathrm{SL}$, Ages are in years unless indicated otherwise

comparison and best-fit re-parameterised von Bertalanffy growthfunction parameters (rVBGF) are shown 
Fig. 2 Annual increment widths follow measurements along transverse sections of otoliths in (a) Lutjanus ehrenbergii, and (b) Pomacanthus maculosus. Photographs were taken under a high-power microscope with transmitted light. Inset shows the annotated transverse section of a fish estimated as 8 years old

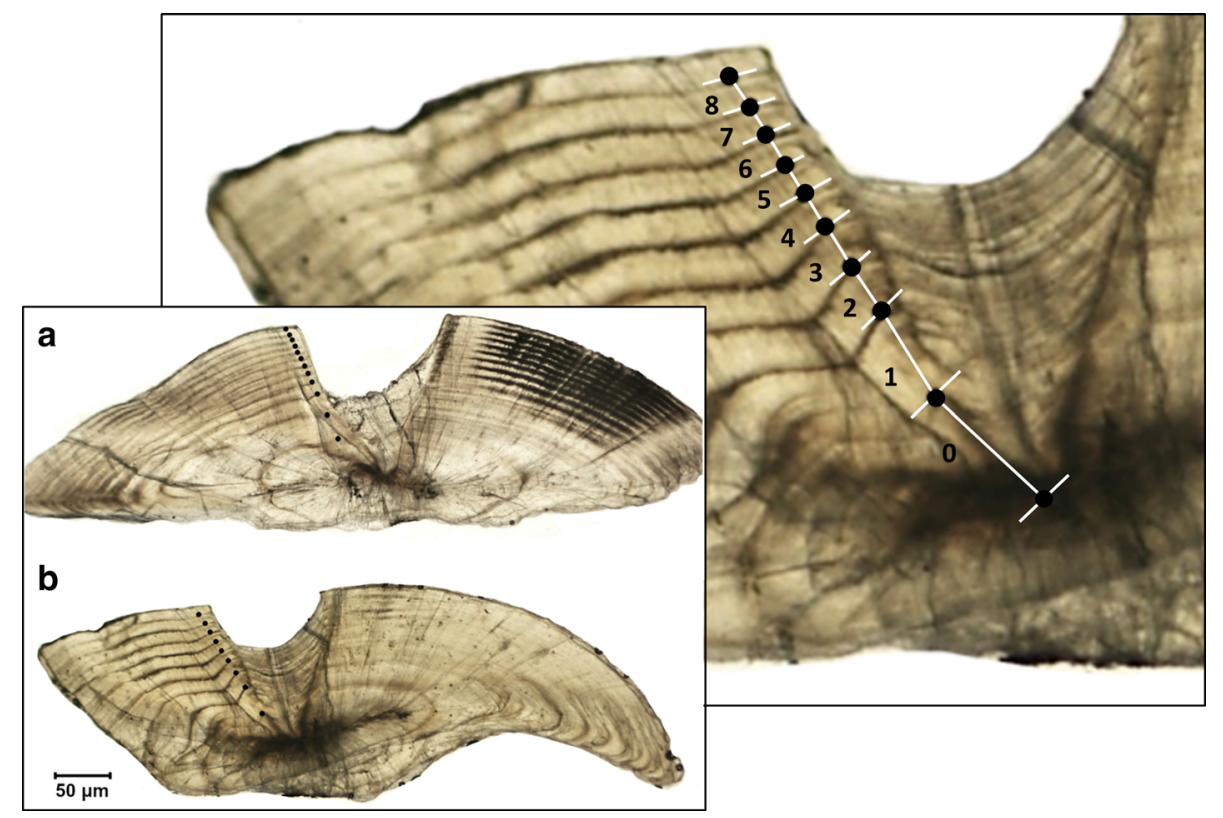

\section{Individual annual growth estimation}

To determine whether yearly growth rate differs within species between regions, annual increment widths were measured and compared between individuals. A subset of the total samples (148 and 144 otoliths of L. ehrenbergii and P. maculosus, respectively; Table 2) that showed clear edges between annual increments and with at least one completed annual increment (i.e. individuals $\geq 2$ years old) were photographed and examined. As otolith growth is an appropriate representation of fish somatic growth in our species (i.e. significant positive relationship between otolith radius and individual body length, see Fig. S1a, b), increment widths were measured $(\mathrm{mm})$ along the dorsal antisulcus axis (from core to edge) using MorphoJ (v1.06). Distances between the outer edges of each annual increment were taken to indicate the width of each consecutive growth increment (Fig. 2a, b). Through back-calculation from age at capture (hereafter 'AAC') and year of capture, age ('Age') and calendar growth year ('Year') were, respectively, assigned to each increment (Table 3). The first two annual increments were not used in the analysis due to poor visualisation in the inner region of the otolith, while the last (marginal) increments were excluded because they did not represent a full year of growth (Martino et al. 2019). For each region, the sample size was at least five increment measurements per calendar year. In total, increment widths were measured from $148 \mathrm{~L}$. ehrenbergii (Arabian Gulf $=58 ;$ Oman Sea $=90)$ and 144 P. maculosus (Arabian Gulf $=107$; Oman Sea $=37$ ) individuals (Table 2). Increment widths encapsulated growth of individuals between 2002 and 2015 in L. ehrenbergii and between 1993 and 2016 in P. maculosus (Table 2).

\section{Growth mixed modelling}

Sources of annual growth variation in P. maculosus and $L$. ehrenbergii were investigated using a series of hierarchical mixed-effects models predicting variation in otolith increment widths (following Morrongiello and Thresher 2015). Growth was modelled separately for the two regions to avoid the co-variation of multiple environmental factors with regions. All mixed modelling was performed in $\mathrm{R}(\mathrm{R}$ core development team 3.5.1, 2019), using the packages lme4 (Bates et al. 2018), effects (Fox 2003), and AICcmodavg (Mazerolle 2019). Modelling could not be done for $P$. maculosus in the Oman Sea due to insufficient sample sizes.

Table 2 Summary of L. ehrenbergii and P. maculosus otolith samples used to develop sclerochronologies

\begin{tabular}{lllclcc}
\hline Species & Area & No. sampled years & No. fish & No. increment measurements & Age range (year) & Range of years \\
\hline L. ehrenbergii & Arabian Gulf & 2 & 58 & 211 & $2-15$ & $2002-2015$ \\
& Oman Sea & 2 & 90 & 368 & $2-16$ & $2003-2015$ \\
P. maculosus & Arabian Gulf & 3 & 107 & 678 & $2-31$ & $1993-2016$ \\
& Oman Sea & 4 & 37 & 119 & $2-22$ & $2002-2016$ \\
\hline
\end{tabular}


Table 3 Descriptions of predictor variables used in the mixed-effects modelling of Lutjanus ehrenbergii and Pomacanthus maculosus's growth

\begin{tabular}{ll}
\hline Parameter & Description \\
\hline Fixed intrinsic effects & Data range \\
Age & Year in which the annual increment was formed \\
Year & Age in years at time of capture. Measure of potential selectivity on growth \\
AAC & Mean annual sea surface temperature $\left({ }^{\circ} \mathrm{C}\right)$ \\
Fixed extrinsic effects & Mean maximum sea surface temperature during the hottest month (Aug) $\left({ }^{\circ} \mathrm{C}\right)$ \\
Mean SST & Mean minimum sea surface temperature during the coldest month (Feb) $\left({ }^{\circ} \mathrm{C}\right)$ \\
Max SST & Mean annual salinity (psu) \\
Min SST & Mean annual chlorophyll-a (mg m $\left.{ }^{-3}\right)$ \\
Salinity & Unique identifier code for each fish \\
Chl-a & Calendar year in which the increment was formed, quantifies inter-annual \\
Random effects & growth variability \\
1 IFishID & Random age slope for FishID random intercept, allows for individual-specific \\
1|Year & differences in the growth - age relationship \\
& Random age slope for Year random intercept, allows for year-dependent \\
AgelFishID & differences in age-specific growth \\
&
\end{tabular}

To explore potential drivers of inter-annual growth variation within the model, we used both intrinsic and extrinsic predictors. Intrinsic predictors (i.e. intra-population drivers) were the fixed effects of Age and AAC, which account for expected age-related trends, bias, and selectivity (Morrongiello and Thresher 2015), while the random effects of FishID and Year were utilized (Table 3 and Supplementary materials-'intrinsic predictors' for details). Extrinsic predictors (i.e. environmental predictors) were mean, maximum and minimum annual SST $\left({ }^{\circ} \mathrm{C}\right)($ 'mean, max and min SST', respectively), annual mean salinity ('salinity', psu) and annual mean chlorophyll-a ('chl-a', mg $\mathrm{m}^{-3}$ ) (Table 3 and Supplementary materials-'extrinsic predictors' for details). Due to the lack of sex data, sex was not used as growth predictor; nevertheless, patterns of sexual dimorphism are known for our species (i.e. female individuals grow larger in L. ehrenbergii, while males grow larger in P. maculosus) (Grandcourt et al. 2010, 2011), and were taken into account during the interpretation of the results.

\section{Model selection}

Growth, Age, and AAC were log-transformed to meet model assumptions. All variables (intrinsic and extrinsic) were mean centred to facilitate the convergence of the model and the interpretation of the random slopes (Morrongiello and Thresher 2015). Analyses were run with a two-stage approach: in the first stage, we built a base set of linear mixed models that encompassed a series of random effect and fixed intrinsic effect structures to identify the optimal intrinsic model (Tables S3-S6 and Supplementary materials-'models selection' for details of models selection, ranking and fitting). In the second stage of the analysis, we investigated whether environmental factors influenced growth. We extended the optimal intrinsic model for each region to include single or combinations between two environmental variables, which were fitted separately and ranked using Akaike's information criterion corrected for small sample sizes $\left(\mathrm{AIC}_{\mathrm{C}}\right)$ (Burnham and Anderson 2004) and $\triangle \mathrm{AIC}_{\mathrm{c}}$ values (Table S7, S8). Interactions between SST effects and between SST and salinity were not included in the model selection as a high level of correlation was expected. Additionally, collinearity between all the remaining combinations was explored using variance inflation factor (VIF) and models with VIF above 3 were removed from comparison (Hair et al. 1998). Finally, linear temporal growth trends were investigated by adding Year as a fixed effect to the optimal intrinsic model.

\section{Results}

\section{Population-level growth, body size and life span}

The age range of $L$. ehrenbergii individuals was similar between regions, ranging between 38 days and 15 years in the Arabian Gulf and 27 days to 16 years in the Oman Sea; whereas $P$. maculosus individuals' age range differed between regions comprising of both younger and older 
individuals in the Arabian Gulf compared to the Oman Sea (9 days to 31 years and 81 days to 22 years, respectively) (Table 1). Although there is no generally applicable target value for precision given variation among species (Campana et al. 2001), the IAPE for L. ehrenbergii and $P$. maculosus was, respectively, 3.9 and $3.5 \%$ which is below the expected value of $5 \%$ in high-volume ageing facilities (Morison et al. 1998).

Both L. ehrenbergii and P. maculosus had consistently smaller asymptotic size and maximum length $\left(\mathrm{L}_{\max }\right)$ in the Arabian Gulf compared with the Oman Sea (Fig. 3a, b; Table 1). Specifically, $\mathrm{L}_{\max }$ of $L$. ehrenbergii and $P$. maculosus individuals was $19 \%$ (linear regression, $\mathrm{F}=153.3, \quad d f=1,49, \quad p<0.001)$ and $13 \%$ smaller $(\mathrm{F}=9.968, d f=1,34, p=0.003)$, respectively. Maximum age $\left(\right.$ Age $\left._{\max }\right)$ was significantly lower in the Arabian Gulf compared to the Oman Sea for L. ehrenbergii ( $\mathrm{F}=4.362$, $d f=1,49, p=0.042$ ), but did not significantly differ between $P$. maculosus populations $(\mathrm{F}=1.859, d f=1,34$, $p=0.182)($ Table 1$)$.

\section{Sources of individual growth variation}

\section{Extrinsic conditions}

The magnitude and temporal trends of extrinsic parameters varied significantly between the Arabian Gulf and the Oman Sea (Fig. 4, Table S1). Both regions recorded relatively high inter-annual variation in min, mean and max SST, while inter-annual variation in salinity was high in the Arabian Gulf but minimal in the Oman Sea. In addition, both regions recorded relatively high inter-annual variation in chlorophyll-a concentrations, which was stronger in the Oman Sea than the Arabian Gulf (Fig. 4a). Despite no difference in annual mean SST between regions, the Arabian Gulf had higher intra-annual SST variation, with temperature significantly colder in winter and warmer in summer compared to the Oman Sea, as well as higher annual mean salinities, and lower annual mean chlorophylla concentrations (Fig. 4b, Table S1).

\section{Growth predictors}

Across species and regions, growth declined with age and salinity (Tables 4 and 5, see Table 4 for random effect structure details). Negative effects of salinity on growth rate were most apparent within the Oman Sea populations of L. ehrenbergii ( $-107.2 \%$ annual growth per unit increase in annual mean salinity $\left[\mathrm{psu}^{-1}\right]$ ), while Arabian Gulf populations of L. ehrenbergii and P. maculosus also showed lower growth with higher levels of salinity $(-30.3 \%$ and $-5.1 \%$ annual growth per unit increase in annual mean salinity $\left[\mathrm{psu}^{-1}\right.$ ], respectively) (Fig. 5a and Table 5).

There was little consistent effect of increasing temperature on growth rate between regions, though regional patterns were apparent (Fig. 5b and Table 5). Water temperature within the Arabian Gulf was positively correlated to growth in both species, with increases in max SST having a predicted effect on $L$. ehrenbergii's growth rate of $+12.7 \%$ per ${ }^{\circ} \mathrm{C}$, and increases in mean SST an effect of $+6.5 \%$ per ${ }^{\circ} \mathrm{C}$ in P. maculosus. There was no effect of temperature on the Oman Sea populations of $L$. ehrenbergii.

\section{Discussion}

We compared the growth of two common coral reef fish $L$. ehrenbergii and P. maculosus between the environmentally extreme Arabian Gulf and comparably benign Oman Sea, and examined the impact of temperature, salinity and primary productivity on the somatic growth of populations within each region. We found that both species were significantly smaller at age and attained a smaller maximum body size within the Arabian Gulf than within the Oman Sea. However, contrary to the expectation that extremes in temperature would be the main driver of somatic size reduction (i.e. consistent with the TSR), reductions in body size were mainly related to variation in salinity. Such results indicate that salinity may be a vital determinant of both species' growth trajectories. In comparison, temperature had a slightly positive effect on growth rates of Arabian Gulf populations of both species, with no measurable effect on Oman Sea fish populations.

In our study, growth declined with higher mean annual salinity across species and regions, indicating the impacts on demography of a highly saline environment are a reduction and, ultimately, truncation of life history. Indeed, together with temperature, food availability and photoperiod, salinity is known to be a major factor in determining fish development and growth (Boeuf and Payan 2001). Moreover, as osmoregulation is energetically costly (i.e. between 2 and $30 \%$ of daily energy expenditure in marine fish) (Boeuf and Payan 2001; Ern et al. 2014; Kultz 2015), changes in salinity may result in significant energy diversion from growth (Boeuf and Payan 2001). Here, we did not observe the expected crossing of growth curve trajectories between populations living in different thermal regime as predicted by the TSR (i.e. faster juvenile growth but earlier asymptotic growth for fish living in warmer environments) (Trip et al 2014), suggesting that salinity and perhaps even productivity are exhibiting a strong influence on differences in growth between regions. Interestingly, growth rates of populations within the Oman Sea, 
Fig. 3 Comparison of reparameterised version of the von Bertalanffy growth function (rVBGF) for Lutjanus ehrenbergii (a) and Pomacanthus maculosus (b) between the Arabian Gulf ('Gulf') and the Oman Sea ('Oman'). Data points: red circles $=$ Arabian Gulf, blue triangles = Oman Sea. Note different scales on the $\mathrm{x}$-axis
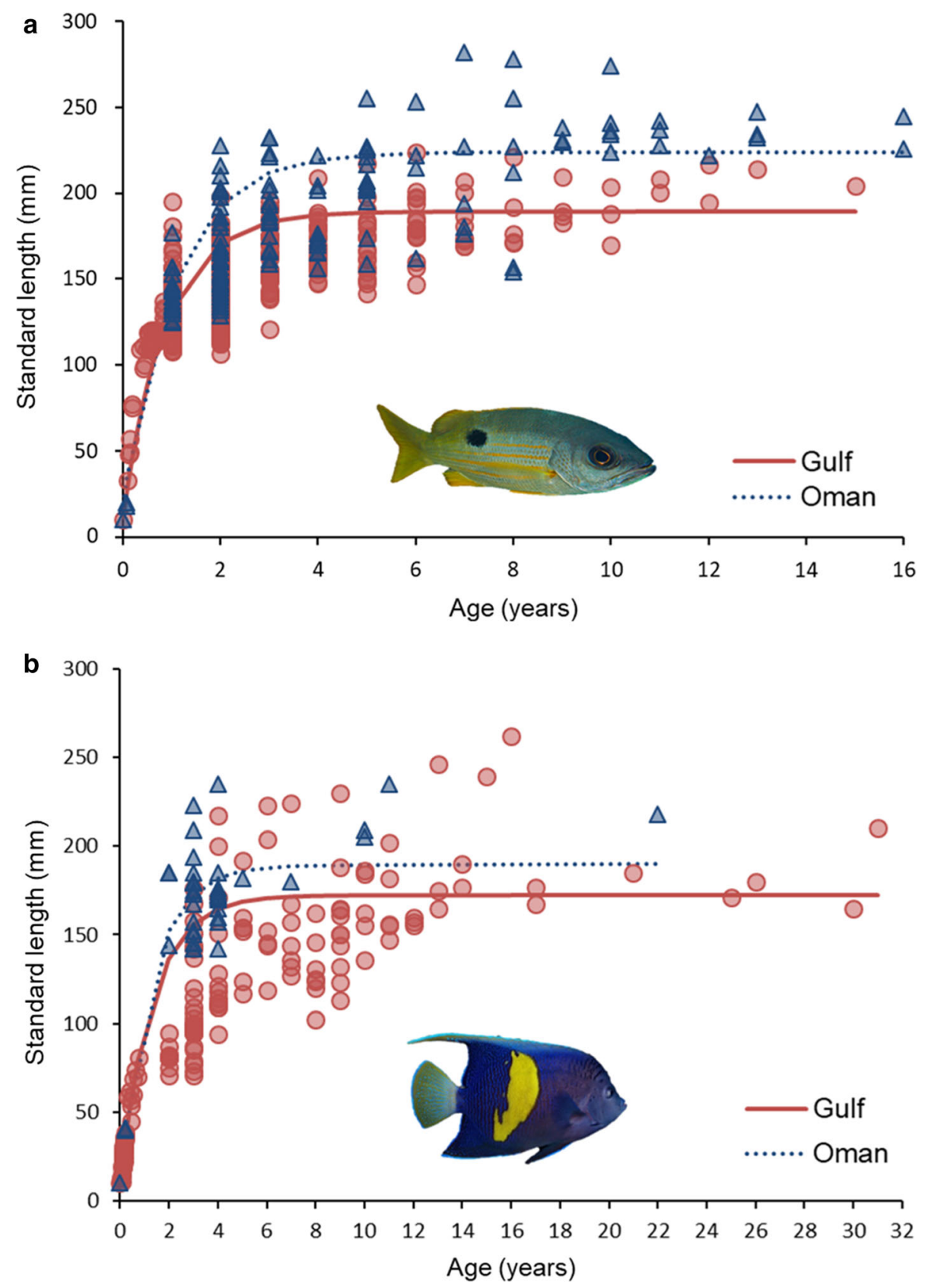

where salinity conditions are predominantly stable, were impacted more strongly by salinity fluctuations compared to populations within the Arabian Gulf, suggesting Arabian Gulf's populations may have higher capability of acclimation to seasonal and interannual changes in environmental conditions (Rummer and Munday 2017; D'Agostino et al. 2019). While numerous studies have examined the implications of increasing temperature and temperature variability on coral reef fish growth (e.g. Munday et al. 2008; Messmer et al. 2017; Taylor et al. 2019), to our knowledge there has been no investigation of the combined effect of increasing temperature and salinity on coral reef fish demography. This is despite the evidence of synergism between the two stressors (Claireaux and Lagarde 1999; Jian et al. 2003) and the likely occurrence of both stressors in already dry regions and hyper-saline (sensu saltier than ocean salinity) semi-enclosed seas in the near future (such as the Arabian Gulf, Red Sea and Mediterranean Sea) (Durack et al. 2012; Skliris et al. 2014; Zika et al. 2018).

Positive effects of high SST on growth rates of both species within the Arabian Gulf may show that high summer water temperatures do not exceed the population's typical temperature range in this region. For example, there 

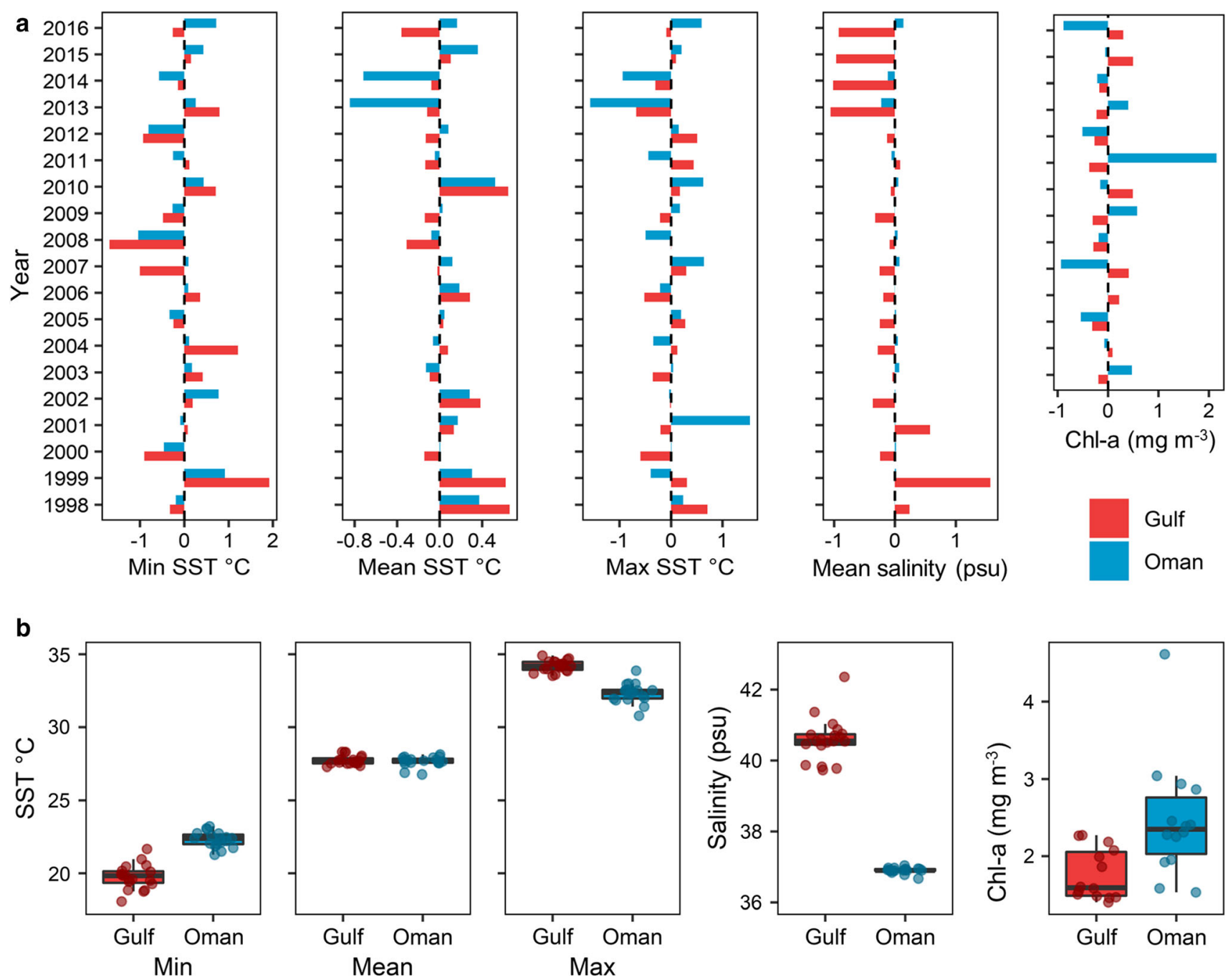

Fig. 4 Intra- (a) and inter- (b) annual variability in sea surface temperature (min, mean and max), salinity and chlorophyll-a between the Arabian Gulf ('Gulf', red) and the Oman Sea ('Oman', blue). In (a) divergent bars quantify the positive/negative annual change of specific environmental variables during a given year from the individual mean (dashed vertical line) across all years. In (b) solid

black line represents the median, with the box indicating the upper and lower quartiles, and whiskers representing the maximum or minimum observed value that is within 1.5 times the interquartile range of the upper or lower quartile, respectively. Dots are individual data points

Table 4 Optimal model structures derived by ranking a series of increasingly complex mixed-effects models

\begin{tabular}{llllll}
\hline Species & Region & Intrinsic model & Fixed effects & Random effects & Best extrinsic covariate structure \\
\hline L. ehrenbergii & Arabian Gulf & $2 \mathrm{a} 2$ & Age + AAC & AgelFishID + 1IYear & Salinity + max SST \\
& Oman Sea & $2 \mathrm{a} 2$ & Age + AAC & AgelFishID + 1IYear & Salinity \\
P. maculosus & Arabian Gulf & $3 \mathrm{a} 1$ & Age & AgelFishID + AgelYear & Salinity + mean SST \\
& Oman Sea & NA & NA & NA & NA \\
\hline
\end{tabular}

In Lutjanus ehrenbergii, the best intrinsic model was similar across regions and included Age and AAC with a random Age slope for FishID. This indicated that the growth-age relationship differed among individuals, while the random intercept for Year indicated growth varied among years. In Pomacanthus maculosus in the Arabian Gulf, the best intrinsic model included only Age as fixed intrinsic factor with random Age slope for FishID and random Age slope for Year, indicating the age-growth relationship differed among years

was a positive effect of increased maximum SST on growth rate of $L$. ehrenbergii, potentially indicating that the Arabian Gulf's summer temperature of $>34^{\circ} \mathrm{C}$ may not exceed the thermal optimum for this species. Indeed, $L$. ehrenbergii abundance and predatory activity appear to be highest in summer (D'Agostino et al. 2019; Vaughan et al. 
Table 5 Fixed effect parameter estimates $( \pm$ SE) and test statistics for optimal models describing intrinsic, temporal and environmental effects on Lutjanus ehrenbergii and Pomacanthus maculosus' growth (see Tables S1-8 for model selection and base models' detail)

\begin{tabular}{|c|c|c|c|c|c|c|c|c|}
\hline \multirow[t]{3}{*}{ Fixed effects parameter } & \multicolumn{4}{|l|}{ Arabian Gulf } & \multicolumn{4}{|l|}{ Oman Sea } \\
\hline & \multicolumn{2}{|l|}{ L. ehrenbergii } & \multicolumn{2}{|l|}{ P. maculosus } & \multicolumn{2}{|l|}{ L. ehrenbergii } & \multicolumn{2}{|c|}{ P. maculosus } \\
\hline & Estimate & $\mathrm{t}$ value & Estimate & $\mathrm{t}$ value & Estimate & t value & Estimate & $\mathrm{t}$ value \\
\hline \multicolumn{9}{|l|}{ Intrinsic effects } \\
\hline Intercept & $-2.20(0.02)$ & -88.84 & $-2.59(0.02)$ & -130.4 & $-2.26(0.04)$ & -56.58 & NA & NA \\
\hline Age & - $1.04(0.05)$ & -19.99 & $-0.82(0.03)$ & -23.61 & $-1.06(0.05)$ & -23.04 & NA & NA \\
\hline $\mathrm{AAC}$ & $0.27(0.06)$ & 4.81 & - & - & $0.15(0.05)$ & 2.9 & NA & NA \\
\hline \multicolumn{9}{|l|}{ Temporal effect } \\
\hline Year & $0.08(0.01)$ & 5.59 & $0.01(0.002)$ & 6.42 & $0.07(0.01)$ & 7.75 & NA & NA \\
\hline \multicolumn{9}{|l|}{ Environmental effects } \\
\hline Salinity & $-0.3(0.09)$ & -3.51 & $-0.05(0.02)$ & -2.18 & - $1.07(0.43)$ & -2.47 & NA & NA \\
\hline SST (mean) & - & - & $0.06(0.04)$ & 1.77 & - & - & NA & NA \\
\hline SST (max) & $0.13(0.08)$ & 1.58 & - & - & - & - & NA & NA \\
\hline
\end{tabular}

2021), suggesting that L. ehrenbergii may still have the aerobic capacity to perform ecological tasks (e.g. swimming, feeding) during the Arabian Gulf's extreme summer temperature. This hypothesis is supported by the results of a recent laboratory temperature tolerance experiment on three cryptobenthic fish species in the Arabian Gulf where Brandl et al. (2020) showed that fish's thermal maximum tolerance limits largely surpass (i.e. between 1 and $2.5^{\circ} \mathrm{C}$ ) the maximum summer temperature recorded in the region (i.e. $36{ }^{\circ} \mathrm{C}$ ). Finally, the positive effect of mean SST on Arabian Gulf populations of $P$. maculosus may suggest that intermediate temperatures experienced during milder winters or slightly warmer springs or autumns may benefit the growth rate of this species (Johansen et al. 2015; Djurichkovic et al. 2019).

The smaller body sizes observed in Arabian Gulf fishes of both species may represent a life-history trade-off between metabolic demands (i.e. increased osmoregulatory cost) and size, with likely flow-on effects to population structure. Although not universally accepted, the gill-oxygen limitation theory (GOLT) states that as gills function as a two-dimensional surface with growth limited by geometrical constraints, any three-dimensional increases in fish body size, and consequent increases in oxygen demand, may not be met by adequate oxygen supply (Pauly and Cheung 2018, but see Audzijonyte et al. 2019). Consequently, larger-bodied individuals may be unable to compensate for increased metabolic demands associated with high salinity and temperature, due to the incapability of the respiratory system to supply enough oxygen. While we did not observe a strong negative effect of max SST (when dissolved oxygen is at its lowest and the oxygen demand at its highest) on fish growth (Shapiro Goldberg et al. 2019), large-bodied individuals are expected to have limited capacity to increase mass-specific maximum metabolic rate in warmer conditions (Messmer et al. 2017; Rubalcaba et al. 2020) and to be more likely to approach their maximum physiological capacity (Pauly and Cheung 2018). Hence, reduced individual body size in the Arabian Gulf may represent a life-history trade-off, whereby survival is enhanced through smaller body size and, therefore, reduced metabolic demands. Additionally, reduced body size was recently observed in cryptobenthic fish species in the Arabian Gulf compared to conspecific in the Oman Sea (Brandl et al. 2020). Here the authors, based on gut content analyses, suggested fish body size reduction was due to a mismatch between individuals elevated energetic costs of living in the extreme environment of the Arabian Gulf and reduced food quality and diversity within this habitat.

Although reductions in body size may play an important role in coping with variable and extreme temperature and salinity, other mechanisms may be involved in facilitating population stability. For example, recent work has highlighted the importance of behavioural and feeding plasticity in coping with the Arabian Gulf's extreme environmental conditions. The pale-tail damselfish ( $\mathrm{Po}$ macentrus trichrourus) appears able to mitigate bioenergetic inefficiency associated with the fluctuating and extreme water temperature within the Arabian Gulf by downregulating costly activities during winter and summer, while upregulating activity and increasing energy stores in spring (D'Agostino et al. 2019). In this respect, $P$. trichrourus, P. maculosus and Pomacentrus aquilis all show a degree of feeding plasticity in the Arabian Gulf (Shraim et al. 2017; D’Agostino et al. 2019), suggesting that such plasticity in feeding may be an important factor in 
a

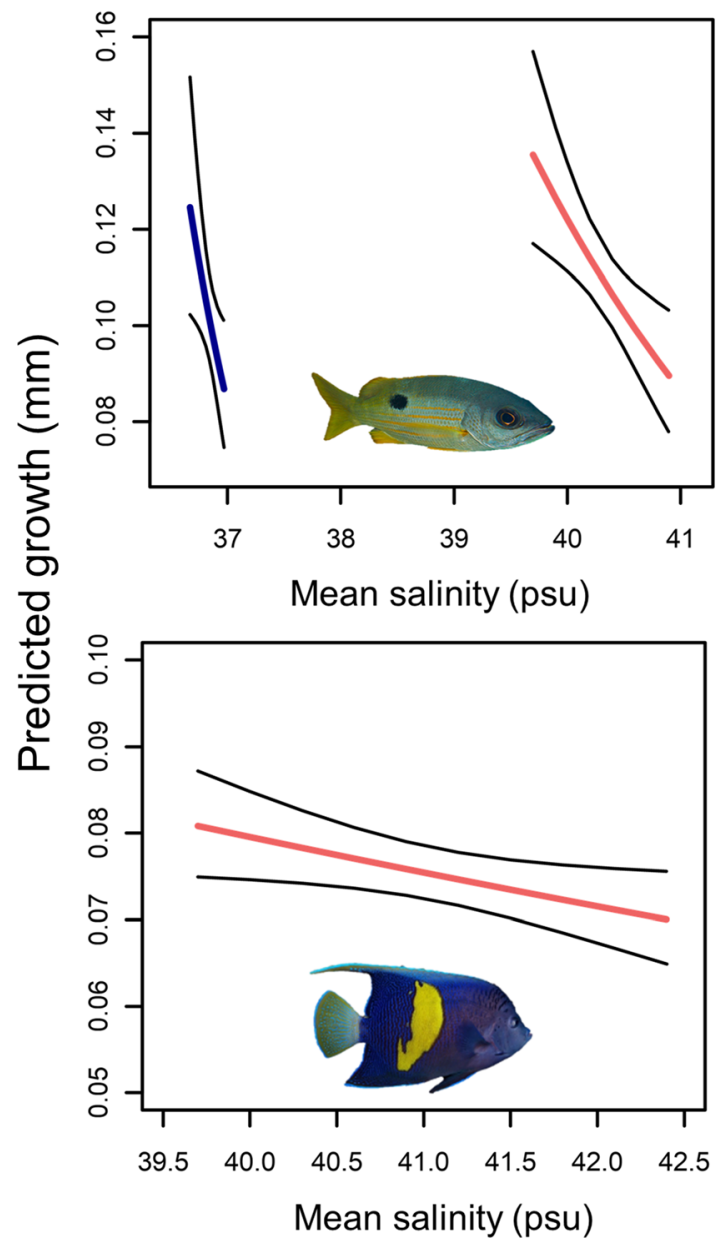

Fig. 5 Predicted effect of annual mean salinity (a) and max and mean sea surface temperature (SST) (b) on the otolith incremental growth of Lutjanus ehrenbergii and Pomacanthus maculosus populations

understanding growth rate and overall body size of all three species.

Reductions in fish body size, within the magnitude of lowered size reported in the present work, are expected to have substantial consequences for trophic interactions, ecosystem function, fisheries and global protein supply (Shackell et al. 2010; Cheung et al. 2013). Fish body sizes are already reducing due to intensive fishing pressure (Stergiou 2002), while there is also evidence to show the potential additive effect of climate change and oxygen limitation on individual (and therefore population) body size spectrum (Cheung et al. 2013; van Rijn et al 2017; Rubalcaba et al. 2020). Notably, theoretical models predict that small reductions in individual body size (i.e. $4 \%$ over 50 years) may lead to a $50 \%$ increase in mortality as well as a $5-35 \%$ reduction in biomass and catch (Audzijonyte et al. 2013). However, most importantly, as fish fecundity exponentially increase with body size, lowered body size is b
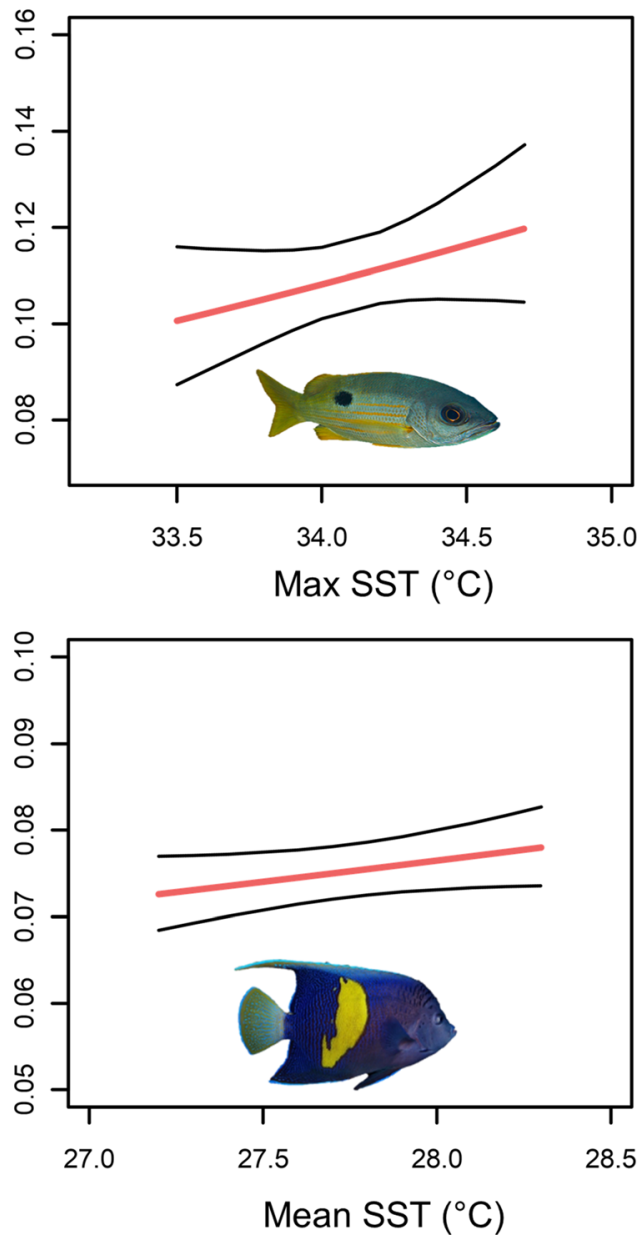

between the Arabian Gulf (red lines) and the Oman Sea (blue line). Black lines indicate $95 \%$ CI. Note different scales on the $y$ and $x$-axis. Predicted effects refer to the model outputs described in Table 4 and 5

expected to have substantial negative consequences on population reproductive output, replenishment and longterm persistence (Baudron 2014; Barneche et al. 2018), which will have cascading effects on the wider ecosystem, potentially impacting coastal economies and threatening food security.

Understanding the mechanisms by which fishes endure the Arabian Gulf's extreme and variable environment will be vital to understand how low latitude coral reef fish populations may cope with predicted changes in their environment. The present work shows that sub-tropical fish communities can persist within extreme environmental conditions, albeit with substantial trade-offs to their life history and demographic structure; individuals of both $L$. ehrenbergii and $P$. maculosus showed smaller size-at-age and lower maximum size in the Arabian Gulf compared with conspecifics in the Oman Sea. Our results suggest that to predict the effect of climate change on fish demography, 
the combined effect of osmoregulatory and thermal stress needs to be considered, especially in regions with limited oceanic exchange and predicted increase in SST and evaporation. Ultimately, to tease apart the effect of extreme temperature and salinity on growth of Arabian Gulf fish populations and establish the role of other potential coping mechanisms (i.e. feeding and behavioural plasticity) in mitigating environmental stressors, laboratory-based physiological-behavioural experiments combining multiple stressors and conditions, while assessing detailed energy budget, are needed.

Acknowledgements This work was funded by a $\mathrm{PhD}$ scholarship from the University of Nottingham to DD and supported by NYU Abu Dhabi Marine Biology Core Technology Platform. JB's funding was supported by the NYUAD Water Research Center, funded by Tamkeen under the NYUAD Research Institute Award (project CG007), while GC's funding were supported by the American University of Sharjah (research Grant FRG19-M-G74). Field fish collection was carried with permission of the Environment Agency, Abu Dhabi (protocol No. EAD-TMBS- RP-0), and according to the NYU-Abu Dhabi animal ethics guidelines. Finally, many thanks to Andrew MacColl, Dan Exton and the anonymous reviewers for useful advice and constructive suggestions.

\section{Compliance with ethical standards}

Conflict of interest On behalf of all authors, the corresponding author states that there is no conflict of interest.

Open Access This article is licensed under a Creative Commons Attribution 4.0 International License, which permits use, sharing, adaptation, distribution and reproduction in any medium or format, as long as you give appropriate credit to the original author(s) and the source, provide a link to the Creative Commons licence, and indicate if changes were made. The images or other third party material in this article are included in the article's Creative Commons licence, unless indicated otherwise in a credit line to the material. If material is not included in the article's Creative Commons licence and your intended use is not permitted by statutory regulation or exceeds the permitted use, you will need to obtain permission directly from the copyright holder. To view a copy of this licence, visit http://creativecommons. org/licenses/by/4.0/.

\section{References}

Atkinson D (1994) Temperature and Organism Size-A Biological Law for Ectotherms? Advances in Ecological Research. pp 1-58 Audzijonyte A, Barneche DR, Baudron AR, Belmaker J, Clark TD, Marshall CT, Morrongiello JR, van Rijn I (2019) Is oxygen limitation in warming waters a valid mechanism to explain decreased body sizes in aquatic ectotherms? Glob Ecol Biogeogr 28:64-77

Audzijonyte A, Fulton E, Haddon M, Helidoniotis F, Hobday AJ, Kuparinen A, Morrongiello J, Smith ADM, Upston J, Waples RS (2016) Trends and management implications of human-influenced life-history changes in marine ectotherms. Fish Fish 17:1005-1028

Audzijonyte A, Kuparinen A, Gorton R, Fulton EA (2013) Ecological consequences of body size decline in harvested fish species: positive feedback loops in trophic interactions amplify human impact. Biol Lett 9:20121103. http://doi.org/10.1098/rsbl.2012. 1103

Audzijonyte A, Richards SA, Stuart-Smith RD, Pecl G, Edgar GJ, Barrett NS, Payne N, Blanchard JL (2020) Fish body sizes change with temperature but not all species shrink with warming. Nature Ecology \& Evolution 4:809-814

Barneche DR, White CR, Marshall DJ (2018) Fish reproductiveenergy output increases disproportionately with body size. Science 645:642-645

Barnes C, Maxwell D, Reuman DC, Jennings S (2010) Global patterns in predator-prey size relationships reveal size dependency of trophic transfer efficiency. Ecology 91:222-232

Bates D, Maechler M, Bolker B, Walker S, Christensem RHB, Singmann H, Dai B, Sheipl F, Grothendieck G (2018) Package 'Ime4.' Version 1:17

Baudron RA, Needle LC, Rijnsdorp DA, Marshall CT (2014) Warming temperatures and smaller body sizes: synchronous changes in growth of North Sea fishes. Glob Chang Biol 20:1023-1031

Bauman AG, Feary DA, Heron SF, Pratchett MS, Burt JA (2013) Multiple environmental factors influence the spatial distribution and structure of reef communities in the northeastern Arabian Peninsula. Mar Pollut Bull 72:302-312

Bellard C, Bertelsmeier C, Leadley P, Thuiller W, Courchamp F (2012) Impacts of climate change on the future of biodiversity. Ecol Lett 15:365-377

Bellwood DR, Hoey AS, Hughes TP (2012) Human activity selectively impacts the ecosystem roles of parrotfishes on coral reefs. Proceedings of the Royal Society B: Biological Sciences 279:1621-1629

Boeuf G, Payan P (2001) How should salinity affect fish growth? Comp Biochem Physiol 130:411-423

Brandl SJ, Johansen JL, Casey JM, Tornabene L, Morais RA, Burt JA (2020) Extreme environmental conditions reduce coral reef fish biodiversity and productivity. Nature Communications 11:3832

Brown CJ, Fulton EA, Hobday AJ, Matear RJ, Possingham HP, Bulman C, Christensen V, Forrest RE, Gehrke PC, Gribble NA, Griffiths SP, Lozano-Montes H, Martin JM, Metcalf S, Okey TA, Watson R, Richardson AJ (2010) Effects of climate-driven primary production change on marine food webs: implications for fisheries and conservation. Glob Change Biol 16:1194-1212

Buchanan JR, Ralph GM, Krupp F, Harwell H, Abdallah M, Abdulqader E, Al-Husaini M, Bishop JM, Burt JA, Choat JH, Collette BB, Feary DA, Hartmann SA, Iwatsuki Y, Kaymaram F, Larson HK, Matsuura K, Motomura H, Munroe T, Russell B, Smith-Vaniz W, Williams J, Carpenter KE (2019) Regional extinction risks for marine bony fishes occurring in the Persian/ Arabian Gulf. Biol Conserv 230:10-19

Burnham KP, Anderson DR (2004) Multimodel inference: understanding AIC and BIC in model selection. Sociol Methods Res 33:261-304

Burt JA, Coles S, van Lavieren H, Taylor O, Looker E, SamimiNamin K (2016) Oman's coral reefs: A unique ecosystem challenged by natural and man-related stresses and in need of conservation. Mar Pollut Bull 105:498-506

Burt JA, Camp EF, Enochs IC, Johansen JL, Morgan KM, Riegl B, Hoey AS (2020) Insights from extreme coral reefs in a changing world. Coral Reefs 39:495-507. https://doi.org/10.1007/s00338020-01966-y

Burt JA, Feary DA, Bauman AG, Usseglio P, Cavalcante GH, Sale PF (2011) Biogeographic patterns of reef fish community structure in the northeastern Arabian Peninsula. ICES J Mar Sci J du Cons $68: 1875-1883$ 
Campana SE (2001) Accuracy, precision and quality control in age determination, including a review of the use and abuse of age validation methods. J Fish Biol 59:197-242

Cheung WWL, Sarmiento JL, Dunne J, Frölicher TL, Lam VWY, Deng Palomares ML, Watson R, Pauly D (2013) Shrinking of fishes exacerbates impacts of global ocean changes on marine ecosystems. Nat Clim Chang 3:254-258

Claireaux G, Lagarde JP (1999) Influence of temperature, oxygen and salinity on the metabolism of the European sea bass. J Sea Res 42:157-168

Coles SL (2003) Coral species diversity and environmental factors in the Arabian Gulf and the Gulf of Oman: a comparison to the Indo-Pacific region. Atoll Reseach Bulletin 1-19

Coles SL, Fadlallah YH (1991) Reef coral survival and mortality at low temperatures in the Arabian Gulf: new species-specific lower temperature limits. Coral Reefs 9:231-237

D'Agostino D, Burt JA, Reader T, Vaughan GO, Chapman BB, Santinelli V, Cavalcante GH, Feary DA (2019) The influence of thermal extremes on coral reef fish behaviour in the Arabian/ Persian Gulf. Coral Reefs 2100:1-12

Daufresne M, Lengfellner K, Sommer U (2009) Global warming benefits the small in aquatic ecosystems. Proc Natl Acad Sci 106:12788-12793

Djurichkovic LD, Donelson JM, Fowler AM, Feary DA, Booth DJ (2019) The effects of water temperature on the juvenile performance of two tropical damselfishes expatriating to temperate reefs. Sci Rep 9:13937

Downing JA, Plante C, Lalonde S (1990) Fish production correlated with primary productivity, not the morphoedaphic index. Can J Fish Aquat Sci 47:1929-1936

Durack PJ, Wijffels SE, Matear RJ (2012) Ocean Salinities Reveal Strong Global Water Cycle Intensification During 1950 to 2000. Science 336:455-458

Ern R, Huong DTT, Cong NV, Bayley M, Wang T (2014) Effect of salinity on oxygen consumption in fishes: a review. J Fish Biol 84:1210-1220

Feary DA, Burt JA, Bauman AG, Usseglio P, Sale PF, Cavalcante GH (2010) Fish communities on the world's warmest reefs: What can they tell us about the effects of climate change in the future? J Fish Biol 77:1931-1947

Feary DA, Pratchett MS, Emslie JM, FowlerFigueiraLuizNakamuraBooth AMWFOJYDJ (2014) Latitudinal shifts in coral reef fishes: why some species do and others do not shift. Fish Fish 15:593-615

Forster J, Hirst AG, Atkinson D (2012) Warming-induced reductions in body size are greater in aquatic than terrestrial species. Proc Natl Acad Sci 109:19310-19314

Fox J (2003) Effect displays for generalized linear models. J Stat Softw 8:1-27

França FM, Benkwitt CE, Peralta G, Robinson JPW, Graham NAJ, Tylianakis JM, Berenguer E, Lees AC, Ferreira J, Louzada J, Barlow J (2020) Climatic and local stressor interactions threaten tropical forests and coral reefs. Philos Trans R Soc B Biol Sci 375:20190116

Francis RICC (1988) Are Growth Parameters Estimated from Tagging and Age-Length Data Comparable? Can J Fish Aquat Sci 45:936-942

Gardner JL, Peters A, Kearney MR, Joseph L, Heinsohn R (2011) Declining body size: a third universal response to warming? Trends Ecol Evol 26:285-291

Gillooly JF, Brown JH, West GB, Savage VM, Charnov EL (2001) Effects of size and temperature on metabolic rate. Science 293:2248-2251

Gordon TAC, Harding HR, Clever FK, Davidson IK, Windsor FM, Armstrong JD, Bardonnet A, Bergman E, Britton JR, Côté IM, D'Agostino D, Greenberg LA, Harborne AR, Kahilainen KK,
Metcalfe NB, Mills SC, Milner NJ, Mittermayer FH, Montorio L, Nedelec SL, Prokkola JM, Rutterford LA, Salvanes AG, Simpson SD, Vainikka A, Pinnegar JK, Santos EM (2018) Fishes in a changing world: learning from the past to promote sustainability of fish populations. J Fish Biol 92:804-827

Grandcourt E, Al Abdessalaam TZ, Francis F, Al Shamsi A (2010) Age-based life history parameters and status assessments of bycatch species (Lethrinus borbonicus, Lethrinus microdon, Pomacanthus maculosus and Scolopsis taeniatus) in the southern Arabian Gulf. J Appl Ichthyol 26:381-389

Grandcourt E, Al Abdessalaam TZ, Francis F, Al Shamsi A (2011) Demographic parameters and status assessments of Lutjanus ehrenbergii, Lethrinus lentjan, Plectorhinchus sordidus and Rhabdosargus sarba in the southern Arabian Gulf. J Appl Ichthyol 27:1203-1211

Grizzle RE, Ward KM, AlShihi RMS, Burt JA (2016) Current status of coral reefs in the United Arab Emirates: Distribution, extent, and community structure with implications for management. Mar Pollut Bull 105:515-523

Haddon M (2001) Modelling and quantitative methods in fisheries. CRC Press, Taylor \& Francis Group, Boca Raton

Hair JF, Black WC, Babin BJ, Anderson RE (1998) Multivariate Data Analysis, 7 edition. Up Saddle River, NJ Prentice Hall 5:207-219

IPCC (2019) Summary for Policymakers. In: IPCC Special Report on the Ocean and Cryosphere in a Changing Climate [Pörtner HO, Roberts DC, Masson-Delmotte V, Zhai P,Tignor M, Poloczanska E, Mintenbeck K, Alegría A, Nicolai M, Okem A, Petzold J, Rama B, Weyer NM (eds.)]. In press

Horne CR, Hirst AG, Atkinson D (2015) Temperature-size responses match latitudinal-size clines in arthropods, revealing critical differences between aquatic and terrestrial species. Ecol Lett $18: 327-335$

Hughes TP, Kerry JT, Baird AH, Connolly SR, Dietzel A, Eakin CM, Heron SF, Hoey AS, Hoogenboom MO, Liu G, McWilliam MJ, Pears RJ, Pratchett MS, Skirving WJ, Stella JS, Torda G (2018) Global warming transforms coral reef assemblages. Nature 556:492-496

Huss M, Lindmark M, Jacobson P, van Dorst RM, Gårdmark A (2019) Experimental evidence of gradual size-dependent shifts in body size and growth of fish in response to warming. Glob Chang Biol 25:2285-2295

IPCC (2007) Synthesis report. Contribution of Working Groups I, II and III to the fourth assessment report. Cambridge University Press, Cambridge

Jian CY, Cheng SY, Chen JC (2003) Temperature and salinity tolerances of yellowfin sea bream, Acanthopagrus latus, at different salinity and temperature levels. Aquac Res 34:175-185

Johansen JL, Steffensen JF, Jones GP (2015) Winter temperatures decrease swimming performance and limit distributions of tropical damselfishes. Conserv Physiol 3:cov039

Kingsolver JG, Huey RB (2008) Size, temperature, and fitness: Three rules. Evol Ecol Res 10:251-268

Kultz D (2015) Physiological mechanisms used by fish to cope with salinity stress. J Exp Biol 218:1907-1914

Martino JC, Fowler AJ, Doubleday ZA, Grammer GL, Gillanders BM (2019) Using otolith chronologies to understand long-term trends and extrinsic drivers of growth in fisheries. Ecosphere 10:1-19

Mazerolle M (2019) AICcmodavg: model selection and multimodel inference based on (Q) AIC (c). R package ver. 2.0-4. https:// cran.r-project.org/web/packages/AICcmodavg/AICcmodavg.pdf

Messmer V, Pratchett MS, Hoey AS, Tobin AJ, Coker DJ, Cooke SJ, Clark TD (2017) Global warming may disproportionately affect larger adults in a predatory coral reef fish. Glob Chang Biol 23:2230-2240 
Morison AK, Robertson SG, Smith DG (1998) An integrated system for production fish aging: image analysis and quality assurance. North Am J Fish Manag 18:587-598

Morrongiello JR, Thresher RE, Hobbs NT (2015) A statistical framework to explore ontogenetic Growth variation among individuals and populations: A marine fish example. Ecol Monogr 85:93-115

Munch SB, Salinas S (2009) Latitudinal variation in lifespan within species is explained by the metabolic theory of ecology. PNAS 106:13860-13864

Munday PL, Kingsford MJ, O'Callaghan M, Donelson JM (2008) Elevated temperature restricts growth potential of the coral reef fish Acanthochromis polyacanthus. Coral Reefs 27:927-931

Neuheimer AB, Thresher RE, Lyle JM, Semmens JM (2011) Tolerance limit for fish growth exceeded by warming waters. Nat Clim Chang 1:110-113

Ohlberger J (2013) Climate warming and ectotherm body size - from individual physiology to community ecology. Funct Ecol 27:991-1001

Parmesan C, Yohe G (2003) A globally coherent fingerprint of climate change impacts across natural systems. Nature 37-42

Pauly D, Cheung WWL (2018) Sound physiological knowledge and principles in modelling shrinking of fishes under climate change. Glob Chang Biol 24:e15-e26

Pörtner HO, Knust R (2007) Climate change affects marine fishes through the oxygen limitation of thermal tolerance. Science 315:95-97

Pratchett MS, Thompson CA, Hoey AS, Cowman PF, Wilson SK (2018) Effects of coral bleaching and coral loss on the structure and function of reef fish assemblages. In: Bleaching C (ed) van Oppen M, Lough J. Springer, Cham, pp 265-293

Randall JE (1995) Coastal Fishes of Oman. University of Hawaii Press, Honolulu

Reynolds RM (1993) Physical oceanography of the Gulf, Strait of Hormuz, and the Gulf of Oman-Results from the Mt Mitchell expedition. Mar Pollut Bull 27:35-59

Reynolds RM (2002) Oceanography. In: Khan N, Munawar M, Price A (eds) The Gulf ecosystem: Health and sustainability. Backhuys Publishers, Leiden, pp 55-64

Riegl BM, Purkis SJ (2012) Coral Reefs of the Gulf: Adaptation to Climatic Extremes in the World's Hottest Sea. In: Riegl B, Purkis S (eds) Coral Reefs of the World, vol 3. Springer, Dordrecht, pp 1-4

Rubalcaba JG, Verberk WCEP, Hendriks AJ, Saris B, Woods HA (2020) Oxygen limitation may affect the temperature and size dependence of metabolism in aquatic ectotherms. PNAS. https:// doi.org/10.1073/pnas.2003292117

Rummer JL, Couturier CS, Stecyk JAW, Gardiner NM, Kinch JP, Nilsson GE, Munday PL (2014) Life on the edge: Thermal optima for aerobic scope of equatorial reef fishes are close to current day temperatures. Glob Chang Biol 20:1055-1066

Rummer JL, Munday PL (2017) Climate change and the evolution of reef fishes: past and future. Fish Fish 18:22-39

Shackell NL, Frank KT, Fisher JA, Petrie B, Leggett WC (2010) Decline in top predator body size and changing climate alter trophic structure in an oceanic ecosystem. Proc R Soc Lond B 277:1353-1360

Shapiro Goldberg D, van Rijn I, Kiflawi M, Belmaker J (2019) Decreases in length at maturation of Mediterranean fishes associated with higher sea temperatures. ICES J Mar Sci 76:946-959

Shraim R, Dieng MM, Vinu M, Vaughan G, McParland D, Idaghdour Y, Burt JA (2017) Environmental Extremes Are Associated with Dietary Patterns in Arabian Gulf Reef Fishes. Front Mar Sci $4: 285$
Skliris N, Marsh R, Josey SA, Good SA, Liu C, Allan RP (2014) Salinity changes in the World Ocean since 1950 in relation to changing surface freshwater fluxes. Clim Dyn 43:709-736

Stenseth NC (2002) Ecological Effects of Climate Fluctuations. Science 297:1292-1296

Stergiou K (2002) Overfishing, tropicalization of fish stocks, uncertainty and ecosystem management: resharpening Ockham's razor. Fish Res 55:1-9

Stock CA, John JG, Rykaczewski RR, Asch RG, Cheung WWL, Dunne JP, Friedland KD, Lam VWY, Sarmiento JL, Watson RA (2017) Reconciling fisheries catch and ocean productivity. PNAS 114:E1441-E1449

Tanner SE, Vieira AR, Vasconcelos RP, Dores S, Azevedo M, Cabral HN, Morrongiello JR (2019) Regional climate, primary productivity and fish biomass drive growth variation and population resilience in a small pelagic fish. Ecol Ind 103:530-541

Taylor BM, Choat JH, DeMartini EE, Hoey AS, Marshell A, Priest MA, Rhodes KL, Meekan MG (2019) Demographic plasticity facilitates ecological and economic resilience in a commercially important reef fish. J Anim Ecol 88:1888-1900

Taylor BM, McIlwain JL (2010) Beyond abundance and biomass: Effects of marine protected areas on the demography of a highly exploited reef fish. Mar Ecol Prog Ser 411:243-258

Taylor SG (2008) Climate warming causes phenological shift in Pink Salmon, Oncorhynchus gorbuscha, behavior at Auke Creek, Alaska. Glob Chang Biol 14:229-235

Trip EDL, Clements KD, Raubenheimer D, Choat JH (2014) Temperature-related variation in growth rate, size, maturation and life span in a marine herbivorous fish over a latitudinal gradient. J Anim Ecol 83:866-875

Trip ELD, Choat JH, Wilson DT, Robertson DR (2008) Inter-oceanic analysis of demographic variation in a widely distributed IndoPacific coral reef fish. Mar Ecol Prog Ser 373:97-109

van Rijn I, Buba Y, DeLong J, Kiflawi M, Belmaker J (2017) Large but uneven reduction in fish size across species in relation to changing sea temperatures. Glob Chang Biol 23:3667-3674

Vaughan GO, Al-Mansoori N, Burt JA (2019) The Arabian Gulf. World Seas: an Environmental Evaluation. Academic Press, pp 1-23

Vaughan GO, Shiels HA, Burt JA (2021) Seasonal variation in reef fish assemblages in the environmentally extreme southern Persian/Arabian Gulf. Coral Reefs. https://doi.org/10.1007/ s00338-020-02041-2

Visconti V, Trip EDL, Griffiths MH, Clements KD (2018) Lifehistory traits of the leatherjacket Meuschenia scaber, a long-lived monacanthid. J Fish Biol 92:470-486

Visser ME, Both C (2005) Shifts in phenology due to global climate change: the need for a yardstick. Proc R Soc B Biol Sci 272:2561-2569

Walther G, Post E, Convey P, Menzel A, Parmesan C, Beebee TJC, Fromentin J, Hoegh-Guldberg O, Bairlein F (2002) Ecological responses to recent climate change. Nature 416:389-395

Wakefield CB, O'Mally JM, Williams AJ, Taylor BM, Nichols RS, Halafihi T, Humphreys RL, Kaltavara J, Nicol SJ, Newman SJ (2017) Ageing bias and precision for deep-water snappers: evaluating nascent otolith preparation methods using novel multivariate comparisons among readers and growth parameter estimates. ICES J Mar Sci 74:193-203

Zika JD, Skliris N, Blaker AT, Marsh R, Nurser AJG, Josey SA (2018) Improved estimates of water cycle change from ocean salinity: The key role of ocean warming. Environ Res Lett 13:074036

Publisher's Note Springer Nature remains neutral with regard to jurisdictional claims in published maps and institutional affiliations. 